It may be noted in passing that the inverse correlation between equatorial spread- $F$ and magnetic activity is also observed in years of sunspot minimum, though not always with the same consistency. A fuller discussion of this phenomenon and of possible explanations for it will be published elsewhere.
A. J. LYON
N. J. SKINNER

University College, Ibadan, Nigeria.

University College of Ghana.

R. W. WRIGHT April 24.

'Wright, R. W., Koster, J. R., and Skinner, N. J., J. Atmos. Terr Phys., 8, 240 (1956).

'Osborne, B. W., J. Atmos. Terr. Phys., 2, 66 (1952).

\section{Distribution of Helium-3 in the Carbo Meteorite}

To make it possible to measure the distribution of helium-3 in the Carbo meteorite, found in Mexico in 1923, Prof. C. Frondel kindly gave permission for the thousand-pound specimen, which is the property of the Harvard Museum, to be cut. The sawing was done at the Watertown Arsenal, Watertown, Mass. A slice, 0.5 in. thick, having an area of about 300 in. ${ }^{2}$, was cut from the centre of the meteorite. Fig. 1 shows a drawing of the slice and of the crosssection of three pieces that had previously been cut from the bottom and now reside in museums. The slice was sectioned into bars, 0.25 in. wide. The helium-3 content was measured in 1 -gm. samples taken from the bars at points indicated by the crosses. The bars are shown by fine lines. The bars adjacent to those we sampled were sent to other experimenters.

Helium-3 and helium-4 had previously been measured $^{1}$ in drillings taken from holes $A$ and $B$ which are approximately parallel and perpendicular to our slice. Our measurements are in good agreement with the previous results for hole $A$.

To measure the helium-3 we used the method of neutron activation ${ }^{2}$ whereby the helium-3 is converted to tritium, which can easily be extracted and counted. The statistical counting error was less than 1 per cent. There is a 10 per cent uncertainty in the calibration for the absolute value of helium-3; however, the relative measurements are more accurate than 5 per cent.

The broken lines in Fig. 1 represent isopleths of helium-3. At some points several measurements were made, and showed fluctuations up to 5 per cent. Further work is necessary to determine whether these fluctuations are real. The isopleths were drawn as smooth curves fitted to the average experimental values. These contours indicate that the Carbo meteorite was a non-spherical object in space.

Two large indentations on the side of the meteorite that yielded the higher helium-3 content exhibited reduced helium-3 values, indicating that these indentations were not present in the meteorite before it entered the Earth's atmosphere. The low helium-3 values found on one side of the specimen indicate that it was originally covered by material that was broken or ablated from the meteorite in its passage through the atmosphere. The lack of argon-39 in the Carbo meteorite ${ }^{s}$ indicates that it landed more than 1,500 years ago; therefore, a slight

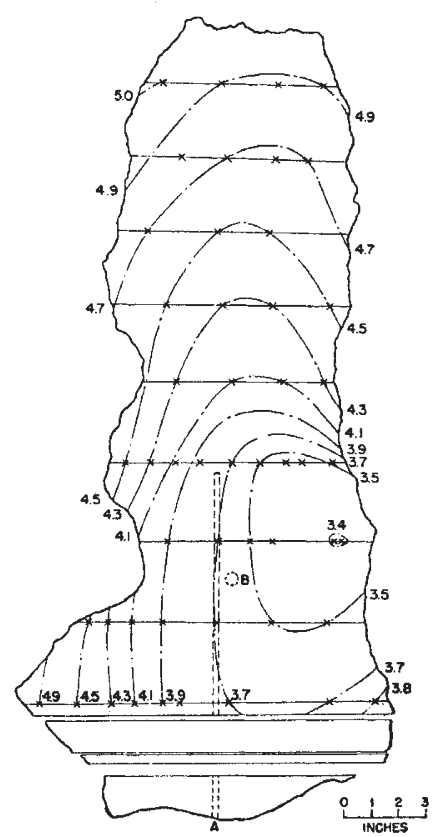
Fig. 1. The hellum-3 distribution in the Carbo meteorite in units
of $10^{-6} \mathrm{~cm} . / \mathrm{gm}$. The points measured are indicated by crosses

possibility exists that the surface has been corroded. The large region of low and nearly constant helium-3, with values of $3.4 \times 10^{-6}$ to $3.7 \times$ $10^{-6} \mathrm{~cm} .{ }^{3} / \mathrm{gm}$., suggests that this area represents the centre of the meteoritic body that existed before it encountered the atmosphere.

Variations in depth of tritium can be produced experimentally ${ }^{4}$ by bombarding long iron targets with protons of known energy. The comparison of these variations with the variations in the distribution of helium-3 in the meteorite suggests certain conclusions about the energy of the bombarding cosmic rays in space. The steepest helium-3 gradients are $4.9-3.9$ in a 4-in. distance from the surface at the base, and $4 \cdot 5-3 \cdot 5$ in a 4-in. distance from the surface near the centre of the slice. Protons with energy less than $5 \mathrm{BeV}$. would produce a steeper gradient ${ }^{3}$ at the surface. The region of low helium-3 content is so large that it also requires an average energy of the cosmic rays greater than $5 \mathrm{BeV}$. If the energy spectrum of the cosmic rays bombarding the Carbo meteorite in space contained the low-energy particles that were observed at the Earth in 1954, then two inches of material must have covered the surface where the helium-3 is high, and a much thicker layer must have covered the surface where the helium-3 is low. The effects of the low-energy rays would be lost with this material.

I am indebted to Prof. Fred L. Whipple for suggesting this problem and for several valuable discussions. This research was assisted by a grant from the U.S. Atomic Energy Commission.

\section{E. L. Frreman}

Smithsonian Astrophysical Observatory, Cambridge, Mass. April 29.

${ }^{1}$ Paneth, F. A., Reasbeck, P., and Mayne, K. I., Nature, 172, 200 (1953).

${ }^{2}$ Fireman, E. I., and Schwarzer, D., Geochim. et Cosmochim. Acta, $11,252(1957)$

Fireman, E. L., Nature, 181, 1613 (1958).

4 Fireman, E. L., and Zahringer, J., Phys. Rev., 107, 1695 (1957). 